\title{
Immune checkpoints and immunotherapy in non-small cell lung cancer: Novel study progression, challenges and solutions (Review)
}

\author{
LIN-RUI MA ${ }^{1 *}$, JIA-XIN LI $^{1 *}$, LING TANG $^{2-4}$, RUN-ZE LI $^{1}$, JIA-SHUN YANG ${ }^{5}$, \\ AO SUN ${ }^{1}$, ELAINE LAI-HAN LEUNG ${ }^{1,6^{*}}$ and PEI-YU YAN ${ }^{1 *}$

\begin{abstract}
${ }^{1}$ Faculty of Chinese Medicine, State Key Laboratory of Quality Research in Chinese Medicines, Macau University of Science and Technology, Macau 999078; ${ }^{2}$ Guangdong Provincial Key Laboratory of Chinese Medicine Pharmaceutics;

${ }^{3}$ Guangdong Provincial Engineering Laboratory of Chinese Medicine Preparation Technology; ${ }^{4}$ School of

Traditional Chinese Medicine, Southern Medical University, Guangzhou, Guangdong 510515; ${ }^{5}$ Department of

${ }^{6}$ Department of Integrated Chinese and Western Medicine, Zhuhai Hospital of Integrated Traditional
\end{abstract} \\ Rehabilitation Medicine, The Third Affiliated Hospital of Southern Medical University, Guangzhou, Guangdong 510630; \\ Chinese and Western Medicine, Zhuhai 519000, P.R. China
}

Received March 16, 2021; Accepted June 4, 2021

DOI: $10.3892 / \mathrm{ol} .2021 .13048$

\begin{abstract}
Lung cancer is the most common type of cancer with the highest mortality rate worldwide. Non-small cell lung cancer (NSCLC) accounts for $\sim 85 \%$ of the total number of lung cancer cases. In the past two decades, immunotherapy has become a more promising treatment method than traditional treatments (surgery, radiotherapy and chemotherapy). Immunotherapy has been shown to improve the survival rate of patients and to have a superior effect when controlling lung cancer than traditional therapy. However, only a small number of patients can benefit from immunotherapy, and not all patients who qualify experience long-term benefits. In the clinic, the objective response rate of programmed cell death protein 1 treatment without the prior screening of patients is only $15-20 \%$. Immunotherapy is associated with both opportunities and challenges for patients with NSCLC. The current challenges of immunotherapy include the lack of accurate biomarkers, inevitable resistance and insufficient understanding of immune checkpoints. In previous years, several methods for overcoming the challenges posed by immunotherapy have been proposed, but combination therapy is the most suitable choice. A large number of studies have
\end{abstract}

Correspondence to: Dr Pei-Yu Yan or Dr Elaine Lai-Han Leung, Faculty of Chinese Medicine, State Key Laboratory of Quality Research in Chinese Medicines, Macau University of Science and Technology, Avenida Wailong, Block H, Macau 999078, P.R. China E-mail: pyyan@must.edu.mo

E-mail: 1hleung@must.edu

${ }^{*}$ Contributed equally

Key words: non-small cell lung cancer, immune checkpoints, biomarker, resistance, combination therapy shown that the combination of drugs can significantly improve their efficacy, compared with monotherapy, and that some therapeutic combinations have been approved by the Food and Drug Administration for the treatment of NSCLC. Traditional Chinese medicine (TCM) is a traditional medical practice in China that can play an important role in immunotherapy. Most agents used in TCM originate from plants, and have the advantages of low toxicity and multiple targets. In addition, TCM includes a unique class of drugs that can improve autoimmunity. Therefore, TCM may be a promising treatment method for all types of cancer.

\section{Contents}

1. Introduction

2. Overview of immune checkpoints in NSCLC

3. Immunotherapy in NSCLC

4. Challenges of immunotherapy in NSCLC

5. Future solutions and research directions for immunotherapy in NSCLC

6. Conclusions

\section{Introduction}

At present, the collective worldwide incidence and mortality rates of all cancers are high, and have become the second leading cause of death (1). Among all cancer types, lung cancer is the most common type of cancer, which accounted for $11.6 \%$ of all cancer cases in 2018 (2). Non-small cell lung cancer (NSCLC) accounts for $\sim 85 \%$ of the total number of lung cancer cases (3). The 5-year survival rate of patients with advanced NSCLC is only $\sim 15 \%$, and the recurrence rate of advanced NSCLC following radical treatment is $>40 \%$ (4). In the past two decades, an increasing number of therapies have been widely considered and studied to improve the survival 
rate and quality of life for patients with advanced or metastatic NSCLC. These treatments include surgery, radiotherapy, chemotherapy, targeted therapy, immunotherapy and combined therapies. Among these treatment options, immunotherapy has become the optimum choice, particularly for patients with advanced or metastatic NSCLC. Immunotherapy can effectively control disease progression and improve survival rates (5), and the use of immune checkpoint inhibitors (ICIs) is an effective immunotherapeutic method (6). Thus, the aim of the present review was to investigate the developments in novel immune checkpoints and immunotherapy, with their associated challenges and potential solutions to these issues.

\section{Overview of immune checkpoints in NSCLC}

Immunotherapy is a type of treatment that uses ICIs to block the immune checkpoint signaling pathway and reactivate $\mathrm{T}$ cells, for the purpose of destroying tumors via the immune system (Fig. 1). The effects of immunotherapy are superior to those of other traditional therapies, rendering it an effective and innovative method for treating cancer (7). However, low response rates and immune-related adverse events (irAEs) have also been observed in patients treated with ICIs. Overcoming these challenges is necessary (8). At present, immune checkpoints, including cytotoxic T-lymphocyte associated protein 4 (CTLA-4), programmed cell death protein 1 (PD-1), programmed death-ligand 1 (PD-L1), T cell immunoglobulin and mucin domain-containing protein 3 (TIM-3), lymphocyte activation gene 3 (LAG-3) and T cell immunoreceptor with Ig and ITIM domains (TIGIT), are a research hotspot (Table I) (9).

CTLA-4. In 1995, CTLA-4 was first discovered to deliver inhibitory immune response signals (10). Leach et al (11) demonstrated that blocking CTLA-4 enhanced the immune-mediated targeting of tumor cells, and that tumor cells had the ability to upregulate the expression of CTLA-4. CTLA-4 belongs to the immunoglobulin superfamily and its gene is localized to chromosome $2 \mathrm{q} 33$ in humans (12). The structure of CTLA-4 is homologous to that of CD28, with which it shares two ligands, CD80 and CD86 (13). Therefore, CTLA-4 and CD28 exert opposing functions. CTLA-4 induces inhibitory signals in $\mathrm{T}$ cells and blocks $\mathrm{T}$ cell responses by competing with CD28 for ligand binding (14). CTLA-4 also regulates T-cell activation through several mechanisms, including the inhibition of T-cell proliferation, differentiation, IL-2 production and cell cycle progression. Therefore, CTLA- 4 serves a significant role in immunotherapy, and has achieved satisfactory results in clinical treatment $(15,16)$.

$P D-1 / P D-L 1$. PD-1 is a member of the CD28 superfamily involved in programmed cell death $(17,18)$, that is preferentially expressed by $\mathrm{T}$ and $\mathrm{B}$ cells, but also expressed in other cell subsets, such as dendritic cells, natural killer (NK) cells and monocytes. PD-1 forms conjugates with PD-L1 and PD-L2, which belong to the B7 protein family, where PD-L1 is its primary ligand (19). PD-1 interacts with PD-L1 to inhibit the activation of $\mathrm{T}$ cells and promote immune escape, since Src homology region 2 -containing protein tyrosine phosphatase 2 inhibits kinases involved in T-cell activation (20).
Although anti-PD-1/PD-L1 inhibitors (that block the binding of PD-1 and PD-L1) have shown encouraging results in the clinic (21), certain challenges remain, including irAEs and low response rates (22).

$L A G-3$. LAG-3 (also known as CD223) was discovered in 1990 and includes Ig-like domains 1-4. Domain 1 contains an additional sequence of $\sim 30$ amino acids known as the 'extra loop' (23). LAG-3 is primarily expressed on $\mathrm{CD}^{+}$ and $\mathrm{CD}^{+} \mathrm{T}$ cells, though plasmacytoid dendritic cells, regulatory $\mathrm{T}$ cells (Tregs), activated B cells and NK T cells also express cell surface LAG-3 (24,25). Stable peptide-major histocompatibility complex class II (MHC-II) is considered to be a ligand of LAG-3 (26), and liver sinusoidal endothelial cell lectin (LSECtin), galectin-3 and fibrinogen-like protein 1 have also been reported as potential LAG-3 ligands $(27,28)$. LAG-3 possesses a similar tumor immune escape mechanism to that of PD-1, and is considered the most important tumor treatment target after PD-1. At present, clinical trials to verify the efficacy of LAG-3 ICIs, alone and combined with other ICIs, are in progress.

TIM-3. TIM-3 is a member of the TIM family of immunoregulatory proteins, first discovered in 2002 (29). TIM-3 is a type I transmembrane protein expressed on $\mathrm{T}$ cells, B cells, NK cells, dendritic cells (DCs) and monocytes (30). Ligands of TIM-3 have been reported to include galectin 9, phosphatidylserine, carcinoembryonic antigen-related cell adhesion molecule 1 (Ceacam1) and high mobility group protein B1 (31). The interaction between TIM-3 and its ligands (galectin-9 or Ceacam1) induces Tyr256 and Tyr263 phosphorylation in the intracellular domain of TIM-3, releasing BAG cochaperone 6 (BAG6) from the TIM-3 tail. The release of BAG6 allows the recruitment of Src kinases (including, but not limited to Lck and Fyn) and promotes the subsequent negative regulation of $\mathrm{T}$ cell receptor signaling $(32,33)$. When TIM-3 is not bound by a ligand, BAG6 is bound to its unphosphorylated cytoplasmic tail, and maintains T-cell activation through Lck recruitment (9). TIM-3 is also co-expressed with PD-1, and the co-blockade of PD-1 and TIM-3 can exert synergistic effects, restoring $\mathrm{T}$ cell effector function and killing tumor cells (34).

TIGIT. TIGIT (also known as WUCAM, Vstm3 and VSIG9) belongs to a constantly expanding family of poliovirus receptor like proteins that plays a critical role in limiting immune functions (35). In 2009, TIGIT was first identified by three groups as an immune checkpoint that inhibits NK and T-cell activation. TIGIT is composed of an extracellular immunoglobulin variable domain, a type I transmembrane domain and two inhibitory motifs of the cytoplasmic tail; one immunoreceptor tyrosine-based inhibitory motif and one immunoglobulin tyrosine tail (ITT)-like motif $(36,37)$. TIGIT has three ligands, CD112, CD113 and CD155, though it binds to CD155 with the highest affinity. In humans, TIGIT is expressed by activated $\mathrm{CD} 4^{+} \mathrm{T}$ and $\mathrm{CD} 8^{+} \mathrm{T}$ cells, Tregs, NK cells and follicular T helper cells. NK cytotoxicity is inhibited by ITT phosphorylation when TIGIT binds to its ligands in NK cells (38). Furthermore, TIGIT-mediated inhibition of effector T and NK cells is also achieved by interfering with 


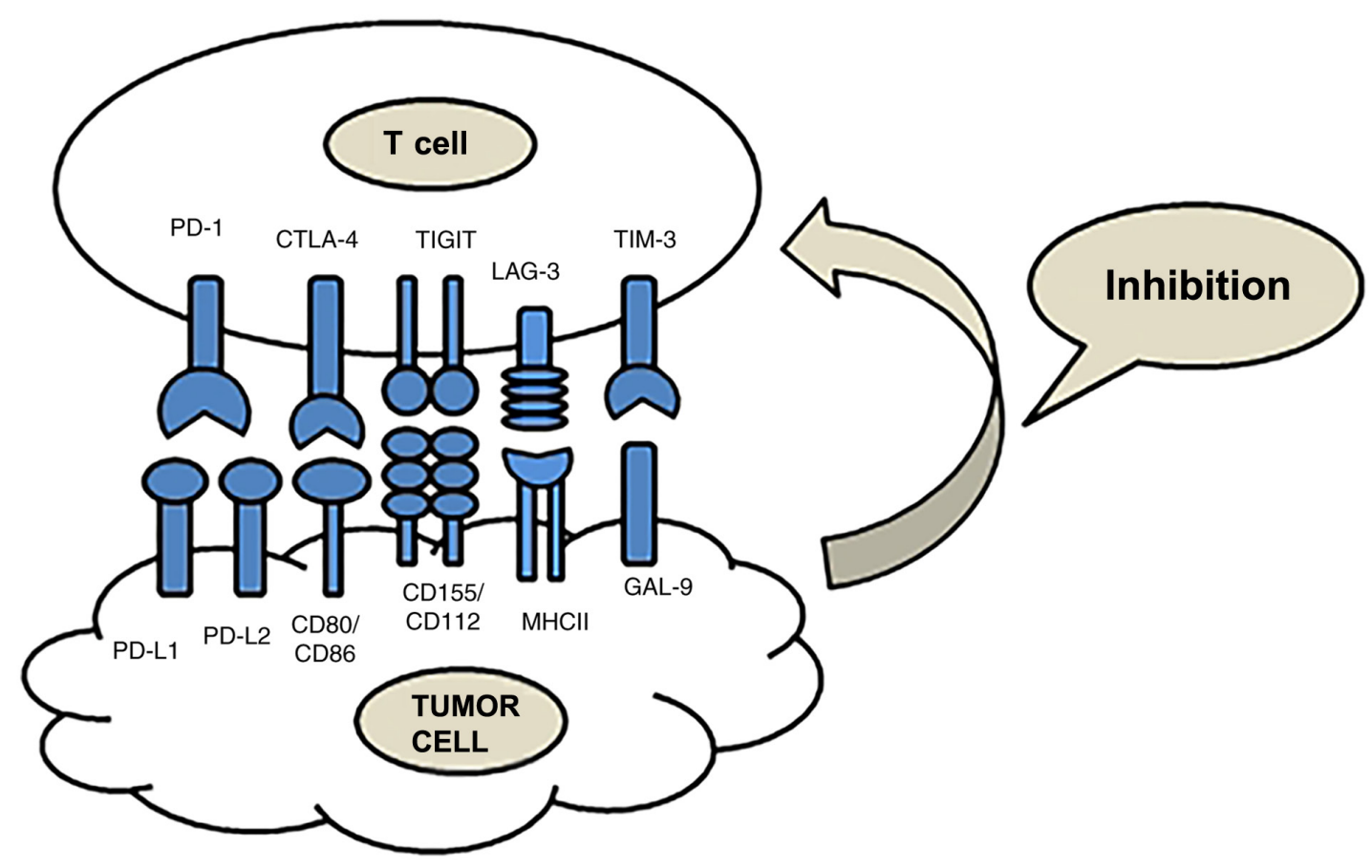

Figure 1. Function and ligands of immune checkpoints. PD-1 and CTLA-4 are classical, and TIM-3, LAG-3 and TIGIT are emerging immune checkpoints. These immune checkpoints are co-inhibitory and can suppress T cell activity. PD-1, programmed cell death protein 1; CTLA-4, cytotoxic T-lymphocyte associated protein 4; TIM-3, T cell immunoglobulin and mucin domain-containing protein 3; LAG-3, lymphocyte-activation gene 3; TIGIT, T cell immunoreceptor with Ig and ITIM domains.

DNAX accessory protein-1 co-stimulation, which directly delivers inhibitory signals to the effector cell (39).

\section{Immunotherapy in NSCLC}

In the current clinical treatment of NSCLC, immunotherapy is primarily centered around two checkpoint inhibitors that target CTLA-4 and PD-1/PD-L1 (40). CTLA-4 is the first ICI to be used in the clinic. In previous years, researchers have paid more attention to PD-1/PD-L1, leading to progress in basic and clinical research. Due to the high toxicity of iplimumab, an ICI of the CTLA-4 signaling pathway, the probability of irAEs increases (41). The drugs approved by the Food and Drug Administration (FDA) for the treatment of NSCLC include pembrolizumab, nivolumab, avelumab, atezolizumab and durvalumab. In addition, there are several novel ICIs in the developmental and clinical research stages $(42,43)$. In conclusion, immunotherapy is associated with both benefits and challenges. It is therefore crucial to overcome the difficulties in expanding the number of individuals who are able to receive treatment, and to improve the efficacy of immunotherapy.

\section{Challenges of immunotherapy in NSCLC}

Although immunotherapy presents a promising treatment option, not all patients can benefit from it, and the benefits may not be long-lasting. In the clinic, the objective response rates (ORRs) of PD-1 treatment without the prior screening of patients is only $15-20 \%$, thus only a proportion of patients with NSCLC are suitable for, and benefit from, immunotherapy (44). The primary reason for the low response rate is that suitable patients are not accurately selected prior to treatment. Therefore, it is essential to identify biomarkers that can predict the efficacy of immunotherapy in patients (45). Of the patients that do benefit from immunotherapy, the majority develop resistance, which has a marked impact on future treatment. Therefore, selecting suitable biomarkers and overcoming resistance is necessary for improving therapeutic effects (46).

\section{Biomarkers}

PD-L1 expression in tumors. PD-L1 is a potential tumor biomarker, and its predictive value varies in different tumors (47). Pembrolizumab has been approved by the FDA as a first-line treatment for patients with NSCLC with PD-L1 expression $\geq 50 \%$, and without EGFR or anaplastic lymphoma kinase (ALK) gene mutations (48). A meta-analysis revealed that the higher the expression level of PD-L1, the greater its benefit in patients using anti-PD-1/PD-L1 (49). However, patients with squamous NSCLC are treated with nivolumab regardless of PD-L1 expression level (50). As a biomarker, PD-L1 expression is not omnipotent. At present, PD-L1 detection is widely employed in the clinic, and can be used as a clinical auxiliary or supplementary diagnostic tool to predict the efficacy of immunotherapy $(51,52)$; however, it is not without its challenges.

PD-L1 is a continuous variable, the levels of which can be altered by induction under constant conditions, for example, by cisplatin. Therefore, accurately detecting the level of PD-L1 is challenging (53). Furthermore, surgical resection and biopsy can impact PD-L1 expression, due to the heterogeneity of the tumor (54). The expression of PD-L1 in surgically-removed sections and lung biopsies was analyzed by SP142 immunohistochemistry (IHC) in 160 patients with NSCLC. The results showed that the expression of PD-L1 in lung biopsies was not 
Table I. Summary of immune checkpoints.

\begin{tabular}{|c|c|c|c|c|c|c|c|}
\hline Checkpoint & $\begin{array}{c}\text { Chromosomal } \\
\text { location }\end{array}$ & $\begin{array}{l}\text { Number of } \\
\text { amino acids }\end{array}$ & $\begin{array}{l}\text { Binding } \\
\text { partner }\end{array}$ & $\begin{array}{l}\text { Binding } \\
\text { partner } \\
\text { expression } \\
\text { location }\end{array}$ & $\begin{array}{c}\text { Receptor } \\
\text { expression }\end{array}$ & Trial & Drugs \\
\hline PD-1 & $2 q 37.3$ & 288 & $\begin{array}{l}\text { PD-L1 } \\
\text { (B7-H1) } \\
\text { PD-L2 } \\
\text { (B7-DC) }\end{array}$ & $\begin{array}{l}\text { Cancer cells, } \\
\text { APCs, } \\
\text { tumor } \\
\text { MDSCs }\end{array}$ & $\begin{array}{l}\text { TILs, effector } \\
\text { T cells, T cells, } \\
\text { regulatory B cells, } \\
\text { NK cells }\end{array}$ & $\begin{array}{l}\text { CheckMate-017 } \\
\text { CheckMate-057 } \\
\text { KEYNOTE-010 } \\
\text { KEYNOTE-021 } \\
\text { KEYNOTE-024 } \\
\text { KEYNOTE-189 } \\
\text { IMpower-131 } \\
\text { IMpower-150 } \\
\text { Pembro-RT } \\
\text { CT02008227 } \\
\text { NCT02125461 } \\
\text { NCT02395172 }\end{array}$ & $\begin{array}{l}\text { Nivolumab } \\
\text { Pembrolizumab } \\
\text { Atezolizumab } \\
\text { Durvalumab } \\
\text { Avelumab } \\
\text { PDR001 } \\
\text { REGN2810 } \\
\text { Y3300054 } \\
\text { Tislelizumab } \\
\text { MGA012 } \\
\text { MEDI4736 } \\
\text { SHR-1210 } \\
\text { AB122 }\end{array}$ \\
\hline CTLA-4 & $2 q 33$ & 239 & $\begin{array}{c}\text { B7-1 } \\
(\mathrm{CD} 80) \\
\text { B7-2 (CD86) }\end{array}$ & $\begin{array}{l}\text { APCs } \\
\text { Tumor } \\
\text { MDSCs }\end{array}$ & $\begin{array}{l}\text { Effector T cells, } \\
\text { Tregs }\end{array}$ & $\begin{array}{l}\text { CheckMate227 } \\
\text { CheckMate-568 }\end{array}$ & $\begin{array}{l}\text { Ipilimumab } \\
\text { Tremelimumab }\end{array}$ \\
\hline LAG-3 & $12 \mathrm{p} 13.32$ & 498 & $\begin{array}{l}\text { MHC-II } \\
\text { Galectin-3 } \\
\text { LSECtin } \\
\text { A-synuclein } \\
\text { FGL1 }\end{array}$ & APCs & $\begin{array}{l}\text { Effector T cells, } \\
\text { Tregs, B cells, } \\
\text { NK cells, DCs }\end{array}$ & $\begin{array}{l}\text { NCT03250832 } \\
\text { NCT02460224 } \\
\text { NCT01968109 } \\
\text { NCT02966548 } \\
\text { NCT03005782 } \\
\text { NCT03459222 }\end{array}$ & $\begin{array}{l}\text { LAG525 } \\
\text { TSR-033 } \\
\text { BMS-986016 } \\
\text { REGN3767 }\end{array}$ \\
\hline TIM-3 & $5 q 33.2$ & 302 & $\begin{array}{l}\text { Galectin-9 } \\
\text { Ceacam-1 } \\
\text { HMGB-1 } \\
\text { PtdSer }\end{array}$ & $\begin{array}{l}\text { APCs } \\
\text { Cancer cells }\end{array}$ & $\begin{array}{l}\text { Effector T cells, } \\
\text { B cells, Tregs } \\
\text { DCs, NK cells, } \\
\text { Monocytes }\end{array}$ & $\begin{array}{l}\text { NCT03099109 } \\
\text { NCT03744468 } \\
\text { NCT02608268 } \\
\text { NCT02817633 }\end{array}$ & $\begin{array}{l}\text { LY3321367 } \\
\text { BGB-A425 } \\
\text { MBG453 } \\
\text { TSR-022 }\end{array}$ \\
\hline TIGIT & $3 q 13.31$ & 244 & $\begin{array}{l}\text { CD155 } \\
\text { CD112 }\end{array}$ & $\begin{array}{l}\text { APCs } \\
\text { Cancer cells }\end{array}$ & $\begin{array}{l}\text { T cells, } \\
\text { NK cells }\end{array}$ & $\begin{array}{l}\text { AB } 154 \\
\text { MTIG7192A } \\
\text { BGB-A1217 }\end{array}$ & $\begin{array}{l}\text { Domvanalimab } \\
\text { Tiragolumab } \\
\text { BGB-A1217 }\end{array}$ \\
\hline
\end{tabular}

PD-1, programmed death 1; PD-L1, programmed cell death ligand-1; PD-L2, programmed cell death ligand-2; CTLA-4, cytotoxic T-lymphocyte antigen-4; TIM-3, T cell immunoglobulin and mucin domain 3; LAG-3, lymphocyte activation gene-3; TIGIT, T cell immunoglobulin and ITIM domain; APC, antigen presenting cell; MDSC, myeloid-derived suppressor cell; LSECtin, liver sinusoidal endothelial cell lectin; MHC-II, major histocompatibility complex-II; FGL1, Fibrinogen Like 1; PtdSer, Phosphatidylserine; Tregs, regulatory T cell.

consistent with that in the surgically-removed sections (overall inconsistency rate, $48 \%$ ), and the expression of PD-L1 in the biopsies was generally lower than that in the sections (55). Finally, the difference between IHC assays also has important implications on PD-L1 detection, as results are inconsistent among different assays. Currently, four IHC assays have been approved by the FDA (28-8, SP263, SP142 and 22C3), and selecting the most suitable one for each patient is crucial. In addition, the scoring system for PD-L1 expression has not been standardized $(56,57)$. In conclusion, clinical detection of PD-L1 demands standardization and improved accuracy.

Tumor mutation burden (TMB). TMB is a potential biomarker for immunotherapy, which is defined as the total number of detected somatic gene coding, base substitution, gene insertion or deletion errors in every million bases ( $\mathrm{Mb}$ ). The principle of TMB in predicting the efficacy of immunotherapy is that tumors with a high TMB may express a greater variety of antigens and have stronger immunogenicity, thus increasing their recognition by, and the killing effect of, cytotoxic CD8 ${ }^{+} \mathrm{T}$ cells. Therefore, tumors with a high TMB are suitable for immunotherapy (58). In terms of clinical trials, CheckMate-568 revealed that patients with a TMB of $>10$ mutations (mut)/Mb had higher ORR and longer progression-free survival (PFS) than those with a TMB of $<10 \mathrm{mut} / \mathrm{Mb}$, regardless of PD-L1 expression level. The results showed that TMB could be used as a prospective biomarker for patients treated with nivolumab combined with 
ipilimumab (59). However, the use of TMB as a biomarker has certain limitations.

In terms of detection methods, whole genome sequencing or whole-exome sequencing (WES) are the standard methods for calculating the TMB (58); their disadvantages include the need for high sample quality, long detection times and high cost, and as such, their wide application in clinical practice is limited (60). A promising and convenient alternative is next-generation sequencing (NGS) (61). In a study by Samstein et al (62), integrated mutation profiling of actionable cancer targets (MSK-IMPACT ${ }^{\mathrm{TM}}$ ) was used to sequence the genome. The results showed that for the majority of tumors treated with ICIs, patients with a higher TMB exhibited a higher survival rate (62) The relevant data also showed that the results of quantification of TMB detected by NGS and WES were correlated (63). The FDA has approved two NGS panels (FoundationOne ${ }^{\circledR} \mathrm{CDx}$ and MSK-IMPACT) to evaluate TMB. Although NGS has its advantages, in-depth research is required in order to improve accuracy in clinical practice before it can become the standard method for TMB determination (64). Secondly, there is no fixed standard TMB cut-off value. Generally speaking, a TMB of $>20 \mathrm{mut} / \mathrm{Mb}$ is considered high, whereas a TMB of $<10 \mathrm{mut} / \mathrm{Mb}$ is considered low. Therefore, it is necessary to determine the optimal cut-off value of each tumor type in more prospective clinical studies and clinical practice (65).

Additionally, $30 \%$ of cancer patients face further challenges, including the inability to obtain tumor tissue, insufficient tumor tissue samples and tumor tissue content not meeting the requirements for detection (66). Therefore, a blood-based assay was developed to measure blood tumor mutation burden (bTMB). Blood detection is safer, less costly, and blood samples are easier to obtain than tumor biopsies. Related studies have confirmed that the bTMB can predict the efficacy of atezolizumab in patients with advanced NSCLC (67). However, other studies have shown that the bTMB cannot evaluate the results of immunotherapy (PFS and ORR). Patients with a low bTMB may also benefit from immunotherapy (68). In addition, recent studies have reported that the maximum somatic allele frequency combined with bTMB has a higher predictive effect than bTMB alone in patients with advanced NSCLC treated with atezolizumab (69). bTMB is therefore not a mature biomarker, and further experimentation is required for clinical verification. Although both TMB and bTMB can predict the efficacy of immunotherapy, there are still several obstacles that need to be overcome, including the specification of the detection platform, and the lack of standardization in the evaluation of TMB and $\mathrm{TTMB}$.

At present, there is no single biomarker that can accurately predict the efficacy and prognosis of immunotherapy. In a clinical setting, PD-L1 and TMB are the most commonly used biomarkers, but there are certain limitations regarding their clinical use. It is therefore crucial to continue investigating existing, and identify novel, biomarkers. For example, tumor-infiltrating lymphocytes (TIL), epithelial-to-mesenchymal transition/inflammation signature score, intestinal flora, microsatellite instability high/deficient mismatch repair, gene expression signatures and tumor-specific genotypes are potential biomarkers currently being explored $(70,71)$. However, the identification of a 'perfect' biomarker is unlikely; therefore, assessing the suitability of patients for immunotherapy based on the comprehensive evaluation of multiple indicators is currently the most effective strategy. A study has shown that a combination of human leukocyte antigen (HLA) class I, CD8 ${ }^{+} \mathrm{T}$ cell infiltration, PD-L1 expression and tumor mutational load is a promising biomarker for predicting the efficacy of anti-PD-1 in the treatment of NSCLC (72). However, this combination still requires considerable clinical verification to confirm its predictive ability. Therefore, the focus of future studies should be not only on identification of novel biomarkers, but also the investigation of the most effective combination of various existing biomarkers.

Immunotherapy-induced resistance. With the development of immunotherapy, the global use of ICIs has increased; however, the development of drug resistance remains a considerable challenge (73). Resistance can be categorized as acquired or primary, with the probability of primary resistance at $\sim 60 \%$ (74). Most patients develop resistance following immunotherapy, which reduces its anticancer effects. Therefore, overcoming resistance is important in improving immunotherapeutic efficacy. Existing literature suggest that the current understanding of resistance mechanisms is limited; the potential mechanisms of resistance (based on existing data) are summarized herein.

Firstly, tumor immunogenicity and TMB are associated with the mechanism of resistance. The necessary conditions for effective immunotherapy include tumor expression of the appropriate antigens and the generation of tumor antigen-specific T cells (75). Tumors with a high immunogenicity (NSCLC, renal cell carcinoma and human melanoma) are more sensitive to immunotherapy $(76,77)$. However, tumors with a low TMB produce fewer tumor antigens and have poor immunogenicity, which negatively impacts the activation of effector T cells, further leading to resistance (78). Prostate cancer has poor immunogenicity and low expression of PD-L1, which is the primary reason for drug resistance (79). Therefore, tumor immunogenicity and TMB are closely associated with the mechanism of resistance. Secondly, immunotherapy restores $\mathrm{T}$ cell function by blocking immune checkpoints. However, if tumor cells cannot be identified by $\mathrm{T}$ cells, drug resistance ensues. The expression of tumor cell MHC-I is necessary for identification of tumor cells by $\mathrm{T}$ cells, and MHC-I loss or downregulation results in tumor immune escape. $\beta_{2} \mathrm{~m}$ is an integral part of the HLA class I molecule, and is necessary for antigen presentation. Mutations in $\beta_{2}$ m limit the recognition of $\mathrm{CD}^{+} \mathrm{T}$ cells, which results in $\mathrm{T}$ cell failure (80). Therefore, a promising solution is to generate synthetic long peptides from tumor-associated antigens, as well as DNA and RNA, in order to develop novel vaccines. The associated mechanism is that the vaccine is transported to MHC-I and MHC-II molecules of antigen-presenting cells, thus promoting CD8 and CD4 T cell responses to overcome resistance (81). In addition, radiotherapy can lead to the independent upregulation of MHC-I, recover antigen presentation and overcome resistance (82). Finally, the pathway of immunosuppression is not only associated with PD-1/PD-L1, but also other pathways with similar functions, such as those of TIM-3, LAG-3, CTLA-4 and B- and T-lymphocyte attenuator (BTLA). In the event of the combined action of these pathways, blockade of one may not be sufficient, as the others pathways will likely compensate for the loss of immunosuppressive signals. Therefore, the combination of multiple ICIs may improve their therapeutic effects (83). In clinical and mouse models, the expression of TIM-3 was 
Table II. First-line treatment of NSCLC.

\begin{tabular}{|c|c|c|c|c|c|c|c|}
\hline Study & $\begin{array}{l}\text { Immunological } \\
\text { pathway }\end{array}$ & Study design & Phase & $\begin{array}{l}\text { Condition or } \\
\text { disease }\end{array}$ & $\begin{array}{l}\text { Objective } \\
\text { response } \\
\text { rate, } \%\end{array}$ & $\begin{array}{l}\text { Median } \\
\text { progression- } \\
\text { free } \\
\text { survival, } \\
\text { months }\end{array}$ & $\begin{array}{l}\text { Median } \\
\text { overall } \\
\text { survival, } \\
\text { months }\end{array}$ \\
\hline CheckMate-227 & CTLA-4/PD-1 & $\begin{array}{l}\text { Nivolumab plus } \\
\text { ipilimumabvs. } \\
\text { chemotherapy }\end{array}$ & III & $\begin{array}{l}\text { Squamous or } \\
\text { non-squamous }\end{array}$ & 45.3 & 7.2 & NR \\
\hline CheckMate-568 & CTLA-4/PD-1 & $\begin{array}{l}\text { Nivolumab plus } \\
\text { ipilimumab }\end{array}$ & II & $\begin{array}{l}\text { Advanced/metastatic } \\
\text { NSCLC }\end{array}$ & 30 & 4.2 & NR \\
\hline Keynote-021 & PD-1 & $\begin{array}{l}\text { Pembrolizumab plus } \\
\text { pemetrexed } \\
\text { carboplatin vs. } \\
\text { pemetrexed carboplatin }\end{array}$ & II & Non-squamous & 56.7 & 24 & NR \\
\hline Keynote-189 & PD-1 & $\begin{array}{l}\text { Pembrolizumab } \\
\text { platinum-pemetrexed vs. } \\
\text { placebo-platinum } \\
\text { pemetrexed }\end{array}$ & II & Non-squamous & 47.6 & 8.8 & NR \\
\hline IMpower-131 & PD-L1 & $\begin{array}{l}\text { Atezolizumab }+ \\
\text { carboplatin+ } \\
\text { paclitaxel vs. } \\
\text { atezolizumab+ } \\
\text { paclitaxel vs. } \\
\text { atezolizumab+ } \\
\text { carboplatin + } \\
\text { nab-paclitaxel vs. } \\
\text { carboplatin }+ \\
\text { nab-paclitaxel }\end{array}$ & III & Squamous & 49 & 6.3 & 14 \\
\hline IMpower-150 & PD-L1 & $\begin{array}{l}\text { Atezolizumab plus } \\
\text { carboplatin } \\
\text { plus paclitaxel vs. } \\
\text { Atezolizumab plus } \\
\text { bevacizumab plus } \\
\text { carboplatin plus } \\
\text { paclitaxel vs. } \\
\text { Bevacizumab plus } \\
\text { carboplatin plus paclitaxel }\end{array}$ & III & Non-squamous & 69.3 & 8.3 & 19.2 \\
\hline Pembro-RT & PD-1 & $\begin{array}{l}\text { Pembrolizumab-SBRT vs. } \\
\text { Pembrolizumab }\end{array}$ & III & Metastatic NSCLC & 36 & 6.6 & 15.9 \\
\hline
\end{tabular}

PD-1, programmed death 1; PD-L1, programmed cell death ligand-1; CTLA-4, cytotoxic T-lymphocyte antigen-4; NSCLC, non-small cell lung cancer.

increased following anti-PD-1 resistance, and the combination of anti-TIM-3 and anti-PD-1 was found to improve survival rates $(84,85)$. Therefore, the combination of multiple ICIs may improve tumor control and overcome resistance.

\section{Future solutions and research directions for immuno- therapy in NSCLC}

Although its affects remain controversial, obtaining a deeper understanding of immunotherapy is necessary for its improvement. Future research directions can be divided into a basic and a clinical aspect. With regard to basic research, key directions may include the identification of novel targets, the effective combination of various biomarkers, and the investigation of resistance mechanisms. Based on current basic research findings, the purpose of clinical research is to combine existing treatment methods to obtain the optimum therapeutic effect. Several studies are currently in progress, which have achieved promising results (Table II), and are described in the following sections. 
Combination of multiple treatment options in clinical research Combination of multiple ICIs for NSCLC therapy. PD-1/PD-L1 is one of the signaling pathways of several immune checkpoints, but various other immune checkpoints perform similar functions. The anti-tumor effect can be improved using a combination of multiple ICIs. The combination of anti-PD-1 and anti-CTLA-4 has been widely studied and shown to yield positive results. CheckMate 012 showed that the efficacy of nivolumab + ipilimumab as a first-line treatment was superior to that of nivolumab alone (86). The phase III clinical study CheckMate 227 confirmed that the efficacy of nivolumab + ipilimumab as a first-line treatment was superior to that of traditional chemotherapy. It was also shown that, in patients with a high TMB, the median PFS of the nivolumab + ipilimumab group was longer than that of the chemotherapy group (7.2 vs. 5.5 months) (87). Furthermore, CheckMate 568 revealed an association between the efficacy of nivolumab + ipilimumab as a first-line treatment, and the expression of PD-L1 and TMB. The results indicated that patients with a TMB of $>10$ mut/Mb had a higher ORR and longer PFS, regardless of PD-L1 expression, providing evidence for the use of TMB as a potential biomarker (5). In addition to the combination of anti-PD-1 and anti-CTLA-4, a number of novel immunotherapy combinations are in the experimental stages.

ICIs combined with chemotherapy. Chemotherapy is a traditional treatment for advanced cancer, which can increase tumor antigen presentation, enhance the activity of effector T cells, and increase the expression of PD-L1 in tumors (88). In addition, the regulatory effect of a variety of chemotherapeutic drugs on immune function has been reported. For example, cisplatin upregulates PD-L1 expression in tumor cells through the PI3K/AKT signaling pathway (53), and pemetrexed can promote the activation of NK cells, increasing the production of IFN- $\gamma$ (89). Also, docetaxel selectively reduces the number of Tregs and prevents immune suppression (90). Therefore, chemotherapy and immunotherapy have a synergistic effect, suggesting that combination therapy has a superior effect to monotherapy.

A number of studies have shown that as a first-line treatment, the therapeutic benefits of immunotherapy combined with chemotherapy are greater than those of chemotherapy alone. KEYNOTE-021 studied the difference in efficacy between pembrolizumab + pemetrexed-carboplatin (PC) and $\mathrm{PC}$ alone. The results showed that the ORR of the combination group was $56.7 \%$, while that of the PC group was $30.2 \%$. Compared with PC alone, PFS and overall survival (OS) following combination therapy also improved significantly (91). Patients were divided into three groups based on first-line treatment: Atezolizumab + carboplatin + paclitaxel, atezolizumab + bevacizumab + carboplatin + paclitaxel $(\mathrm{ABCP})$ and bevacizumab + carboplatin + paclitaxel $(\mathrm{BCP})$ as. In the ITT-WT population (patients with EGFR or ALK alterations were excluded), the mPFS of the ABCP group was significantly higher than that of the BCP group (8.3 vs. 6.8 months). In the WT population which had high expression of an effector T cell (Teff) gene signature in the tumor (Teff-high WT) cases, the mPFS of the two groups was 11.3 and 6.8 months. The results showed that adding atezolizumab to bevacizumab + chemotherapy for non-squamous metastatic NSCLC improved OS and PFS, regardless of PD-L1 expression. In December 2018, the FDA approved atezolizumab + carboplatin + paclitaxel + bevacizumab as a first-line treatment option for patients with advanced metastatic NSCLC without EGFR and ALK mutations (92).

ICIs combined with radiotherapy. For patients with advanced NSCLC, radiotherapy is one of the most conventional and effective treatments, and improves survival rate by increasing the control of primary tumour (93). Radiotherapy can increase tumor antigen release, enhance antigen presentation and promote $\mathrm{T}$-cell infiltration into the tumor tissue, thus enhancing the systemic anti-tumor immune response and altering the tumor microenvironment (94). Radiotherapy can induce immunogenic cell death, enhance the TIL repertoire and upregulate MHC and PD-L1 expression $(95,96)$. In immunotherapy, the expression of PD-L1 plays an important role in predicting the therapeutic effect. A previous study revealed that radiotherapy increases the expression of PD-L1 in tumor cells by activating the PI3K/AKT and STAT3 signaling pathways. In addition, radiotherapy is less toxic, and thus a more favorable option for combined immunotherapy (97).

At present, there are few NSCLC clinical studies on radiotherapy combined with ICIs. PEMBRO-RT is a recent multi-center phase II randomized clinical trial, the purpose of which was to determine whether the use of stereotactic body radiotherapy before pembrolizumab treatment increases the anti-tumor response of patients with metastatic NSCLC. The patients in the experimental arm were treated with pembrolizumab following stereotactic body radiotherapy at a single tumor site, while the control arm were treated with pembrolizumab only. The results showed that the ORR at 12 weeks in the experimental arm was significantly higher than that of the control arm (36 vs. 18\%). The mPFS of the experimental arm was 6.6 months, and that of the control arm was 1.9 months. The median OS was 7.6 in the control arm, and 15.9 months in the experimental arm. Although the experimental results showed that the ORR following combination therapy was significantly higher than that of the control arm, the results did not reach the expected standard. In addition, different patient PD-L1 expression levels may also have effeced the experimental results. Therefore, these findings require further experimental confirmation (98). However, based on the existing experimental outcomes, immunotherapy combined with radiotherapy is superior to radiotherapy alone, and does not increase the number of adverse reactions.

ICIs combined with Traditional Chinese Medicine (TCM). In patients with NSCLC, combined immunotherapy can compensate for the deficiencies of immunotherapy alone, allowing increased benefit to a greater number of patients. Combined immunotherapy appears promising, but the current thinking cannot be limited by the existing programs when investigating this research area. TCM has a long history of use in China (99). During the novel coronavirus outbreak in 2020, the majority of hospitals in China used a combination of western and TCM to treat patients, with successful results (100). China has also achieved encouraging results in providing TCM treatment for patients in other countries, which has become an important player in 
global disease treatment (101). The tumor environment is an important consideration when treating tumors, as changes therein may directly affect tumor cell proliferation rate, and subsequently, the effects of immunotherapy and occurrence of resistance (102). For the treatment of cancer, TCM has the potential to improve the tumor environment for increased treatment efficacy. Most TCM agents are derived from plants, and thus, have the advantages of low toxicity and multiple targets(diversity of compounds). In addition, TCM includes a specific class of drugs for the improvement of self-immunity, which improve the tumor environment; as such, the primary purpose of systematic treatment for patients with metastatic NSCLC is to reduce the burden of cancer symptoms, and to improve survival, while also maintaining patient quality of life (103). Currently, traditional treatments and immunotherapy cannot achieve satisfactory results in patients with metastatic NSCLC. Therefore, the use of TCM combined with these other treatment types is a promising option for patients with NSCLC, and research into the role of TCM in immunotherapy is ongoing.

Astragalus polysaccharide (PG2) is the active component of the dried roots of Astragalus membranaceus. A study showed that PG2 increased the M1/M2 macrophage polarization ratio of $\mathrm{H} 441$ and $\mathrm{H} 1299$ cells. It also increased the $\mathrm{T}$ cell-mediated antitumor immune response by promoting the functional maturity of DCs (104). Adding PG2 to cisplatin, a conventional chemotherapeutic drug, can synergistically increase the antitumor effect (105). According to the above theory, the effective results of immunotherapy combined with PG2 in NSCLC were expected (106). Phytolacca acinosa polysaccharides I (PAP-1) is a compound of Phytolacca, which has been proven to affect immune functions in mice. It can also enhance the production of IL-2 and NK cytotoxic factor, and exerts antitumor activity (107). It has also been reported that total glucosides of paeony can regulate the expression of PD-1 and PD-L1 in peripheral blood monocytes (108). Thus to conclude, TCM has the potential to positively influence immunotherapy. In addition, various other TCM agents can regulate immunity and antitumor effects. At present, research on the antitumor effects of combining TCM with immunotherapy is being conducted, the findings of which may provide patients with further treatment options and superior benefits.

\section{Conclusions}

For future clinical trials in cancer, several challenges need to be overcome, including irAEs, low patient response rates and tumor cell resistance to treatment. Although immunotherapy is currently the best option, more promising treatments are expected to arise from ongoing basic and clinical research. Until then, solutions to these problems can be found through the continuous identification of immune checkpoints, and the creation of more favorable combination treatment methods. The research and application of immunotherapy have broad prospects; the discovery of new immune checkpoints and continuous attempts at combination treatments, including that of TCM and immunotherapy, may well be hotspots of future research on NSCLC.

\section{Acknowledgements}

No applicable.

\section{Funding}

The author(s) disclose receipt of the following financial support for the research, authorship, and/or publication of this article: The present study was funded by The Science and Technology Development Fund, Macau SAR (grant no. 0011/2021/A) and The Faculty Research Grant Projects of Macau University of Science and Technology (grant no. FRG-19-028-FC).

\section{Availability of data and materials}

No applicable.

\section{Authors' contributions}

PYY and ELHL conceived and designed the study. LRM and JXL wrote the paper. RZL, LT, JSY and AS revised the paper for important intellectual content. Data authentication is not applicable. All authors read and approved the final manuscript.

\section{Ethics approval and consent to participate}

No applicable.

\section{Patient consent for publication}

No applicable.

\section{Competing interests}

The authors declare that they have no competing interests.

\section{References}

1. Ferlay J, Colombet M, Soerjomataram I, Mathers C, Parkin DM, Piñeros M, Znaor A and Bray F: Estimating the global cancer incidence and mortality in 2018: GLOBOCAN sources and methods. Int J Cancer 144: 1941-1953, 2019.

2. Bray F, Ferlay J, Soerjomataram I, Siegel RL, Torre LA and Jemal A: Global cancer statistics 2018: GLOBOCAN estimates of incidence and mortality worldwide for 36 cancers in 185 countries. CA Cancer J Clin 68: 394-424, 2018.

3. Gridelli C, Rossi A, Carbone DP, Guarize J, Karachaliou N, Mok T, Petrella F, Spaggiari L and Rosell R: Non-small-cell lung cancer. Nat Rev Dis Primers 1: 15009, 2015.

4. Zheng YW, Li RM, Zhang XW and Ren XB: Current adoptive immunotherapy in non-small cell lung cancer and potential influence of therapy outcome. Cancer Invest 31: 197-205, 2013.

5. Herbst RS, Morgensztern D and Boshoff C: The biology and management of non-small cell lung cancer. Nature 553: 446-454, 2018.

6. Bagchi S, Yuan R and Engleman EG: Immune checkpoint inhibitors for the treatment of cancer: Clinical impact and mechanisms of response and resistance. Annu Rev Pathol 16: 223-249, 2021.

7. Somasundaram A and Burns TF: The next generation of immunotherapy: Keeping lung cancer in check. J Hematol Oncol 10: 87, 2017.

8. Shi T, Ma Y, Yu L, Jiang J, Shen S, Hou Y and Wang T: Cancer immunotherapy: A focus on the regulation of immune checkpoints. Int J Mol Sci 19: 1389, 2018.

9. Joller N and Kuchroo VK: Tim-3, Lag-3, and TIGIT. Curr Top Microbiol Immunol 410: 127-156, 2017.

10. Tivol EA, Borriello F, Schweitzer AN, Lynch WP, Bluestone JA and Sharpe AH: Loss of CTLA-4 leads to massive lymphoproliferation and fatal multiorgan tissue destruction, revealing a critical negative regulatory role of CTLA-4. Immunity 3: 541-547, 1995. 
11. Leach DR, Krummel MF and Allison JP: Enhancement of antitumor immunity by CTLA-4 blockade. Science 271: 1734-1736, 1996.

12. Ostrov DA, Shi W, Schwartz JC, Almo SC and Nathenson SG Structure of murine CTLA- 4 and its role in modulating T cell responsiveness. Science 290: 816-819, 2000.

13. Iida T, Ohno H, Nakaseko C, Sakuma M, Takeda-Ezaki M, Arase H, Kominami E, Fujisawa T and Saito T: Regulation of cell surface expression of CTLA-4 by secretion of CTLA-4-containing lysosomes upon activation of $\mathrm{CD}^{+} \mathrm{T}$ cells. J Immunol 165: 5062-5068, 2000.

14. Sharpe AH and Freeman GJ: The B7-CD28 superfamily. Nat Rev Immunol 2: 116-126, 2002.

15. Buchbinder EI and Desai A: CTLA-4 and PD-1 pathways: Similarities, differences, and implications of their inhibition. Am J Clin Oncol 39: 98-106, 2016.

16. de Miguel M and Calvo E: Clinical challenges of immune checkpoint inhibitors. Cancer Cell 38: 326-333, 2020.

17. Ishida Y, Agata Y, Shibahara K and Honjo T: Induced expression of PD-1, a novel member of the immunoglobulin gene superfamily, upon programmed cell death. EMBO J 11: 3887-3895, 1992.

18. Yamazaki T, Akiba H, Iwai H, Matsuda H, Aoki M, Tanno Y, Shin T, Tsuchiya H, Pardoll DM, Okumura K, et al: Expression of programmed death 1 ligands by murine T cells and APC. J Immunol 169: 5538-5545, 2002.

19. Patel SP and Kurzrock R: PD-L1 expression as a predictive biomarker in cancer immunotherapy. Mol Cancer Ther 14 847-856, 2015.

20. Yokosuka T, Takamatsu M, Kobayashi-Imanishi W Hashimoto-Tane A, Azuma M and Saito T: Programmed cell death 1 forms negative costimulatory microclusters that directly inhibit $\mathrm{T}$ cell receptor signaling by recruiting phosphatase SHP2 J Exp Med 209: 1201-1217, 2012

21. O'Kane GM, Labbé C, Doherty MK, Young K, Albaba H and Leighl NB: Monitoring and management of immune-related adverse events associated with programmed cell death protein-1 axis inhibitors in lung cancer. Oncologist 22: 70-80, 2017.

22. Wang L, Ma Q, Yao R and Liu J: Current status and development of anti-PD-1/PD-L1 immunotherapy for lung cancer. Int Immunopharmacol 79: 106088, 2020

23. Huard B, Mastrangeli R, Prigent P, Bruniquel D, Donini S, El-Tayar N, Maigret B, Dréano M and Triebel F: Characterization of the major histocompatibility complex class II binding site on LAG-3 protein. Proc Natl Acad Sci USA 94: 5744-5749, 1997.

24. Anderson AC, Joller N and Kuchroo VK: Lag-3, Tim-3, and TIGIT: Co-inhibitory receptors with specialized functions in immune regulation. Immunity 44: 989-1004, 2016

25. Byun HJ, Jung WW, Lee DS, Kim S, Kim SJ, Park CG, Chung HY and Chun T: Proliferation of activated CD1d-restricted NKT cells is down-modulated by lymphocyte activation gene- 3 signaling via cell cycle arrest in S phase. Cell Biol Int 31: 257-262, 2007.

26. Maruhashi T, Okazaki IM, Sugiura D, Takahashi S, Maeda TK Shimizu K and Okazaki T: LAG-3 inhibits the activation of $\mathrm{CD}^{+} \mathrm{T}$ cells that recognize stable pMHCII through its conformation-dependent recognition of pMHCII. Nat Immunol 19 : $1415-1426,2018$

27. Wang J, Sanmamed MF, Datar I, Su TT, Ji L, Sun J, Chen L, Chen Y, Zhu G, Yin W, et al: Fibrinogen-like protein 1 is a major immune inhibitory ligand of LAG-3. Cell 176: 334-347.e12, 2019

28. Kouo T, Huang L, Pucsek AB, Cao M, Solt S, Armstrong T and Jaffee E: Galectin-3 shapes antitumor immune responses by suppressing $\mathrm{CD} 8^{+} \mathrm{T}$ cells via LAG-3 and inhibiting expansion of plasmacytoid dendritic cells. Cancer Immunol Res 3: 412-423, 2015.

29. Tang R, Rangachari M and Kuchroo VK: Tim-3: A co-receptor with diverse roles in $\mathrm{T}$ cell exhaustion and tolerance. Semin Immunol 42: 101302, 2019.

30. Acharya N, Sabatos-Peyton C and Anderson AC: Tim-3 finds its place in the cancer immunotherapy landscape. J Immunother Cancer 8: e000911,2020.

31. Das M, Zhu C and Kuchroo VK: Tim-3 and its role in regulating anti-tumor immunity. Immunol Rev 276: 97-111, 2017.

32. Huang YH, Zhu C, Kondo Y, Anderson AC, Gandhi A, Russell A, Dougan SK, Petersen BS, Melum E, Pertel T, et al: CEACAM1 regulates TIM-3-mediated tolerance and exhaustion. Nature 517: 386-390, 2015

33. Zhu C, Anderson AC, Schubart A, Xiong H, Imitola J, Khoury SJ, Zheng XX, Strom TB and Kuchroo VK: The Tim-3 ligand galectin-9 negatively regulates $\mathrm{T}$ helper type 1 immunity. Nat Immunol 6: 1245-1252, 2005.
34. Sakuishi K, Apetoh L, Sullivan JM, Blazar BR, Kuchroo VK and Anderson AC: Targeting Tim-3 and PD-1 pathways to reverse T cell exhaustion and restore anti-tumor immunity. J Exp Med 207: 2187-2194, 2010.

35. Stanietsky N, Simic H, Arapovic J, Toporik A, Levy O, Novik A, Levine Z, Beiman M, Dassa L, Achdout $\mathrm{H}$, et al: The interaction of TIGIT with PVR and PVRL2 inhibits human NK cell cytotoxicity. Proc Natl Acad Sci USA 106: 17858-17863, 2009.

36. Yu X, Harden K, Gonzalez LC, Francesco M, Chiang E, Irving B, Tom I, Ivelja S, Refino CJ, Clark $\mathrm{H}$, et al: The surface protein TIGIT suppresses $\mathrm{T}$ cell activation by promoting the generation of mature immunoregulatory dendritic cells. Nat Immunol 10: 48-57, 2009.

37. Boles KS, Vermi W, Facchetti F, Fuchs A, Wilson TJ, Diacovo TG, Cella M and Colonna M: A novel molecular interaction for the adhesion of follicular CD4 T cells to follicular DC. Eur J Immunol 39: 695-703, 2009.

38. He Y, Peng H, Sun R, Wei H, Ljung gren HG, Yokoyama WM and Tian Z: Contribution of inhibitory receptor TIGIT to NK cell education. J Autoimmun 81: 1-12, 2017.

39. Johnston RJ, Comps-Agrar L, Hackney J, Yu X, Huseni M, Yang Y, Park S, Javinal V, Chiu H, Irving B, et al: The immunoreceptor TIGIT regulates antitumor and antiviral CD8(+) T cell effector function. Cancer Cell 26: 923-937, 2014

40. Herzberg B, Campo MJ and Gainor JF: Immune checkpoint inhibitors in non-small cell lung cancer. Oncologist 22: 81-88, 2017.

41. Zhang P, Xiong X, Rolfo C, Du X, Zhang Y, Yang H, Russo A, Devenport M, Zhou P, Liu Y and Zheng P: Mechanism- and immune landscape-based ranking of therapeutic responsiveness of 22 major human cancers to next generation anti-CTLA-4 antibodies. Cancers (Basel) 12: 284, 2020.

42. Kazandjian D, Suzman DL, Blumenthal G, Mushti S, He K, Libeg M, Keegan P and Pazdur R: FDA approval summary: Nivolumab for the treatment of metastatic non-small cell lung cancer with progression on or after platinum-based chemotherapy. Oncologist 21: 634-642, 2016

43. Akinleye A and Rasool Z: Immune checkpoint inhibitors of PD-L1 as cancer therapeutics. J Hematol Oncol 12: 92, 2019.

44. Mathew M, Enzler T, Shu CA and Rizvi NA: Combining chemotherapy with PD-1 blockade in NSCLC. Pharmacol Ther 186 130-137, 2018

45. Cyriac $\mathrm{G}$ and Gandhi L: Emerging biomarkers for immune checkpoint inhibition in lung cancer. Semin Cancer Biol 52 (Pt 2): 269-277, 2018.

46. Topalian SL, Hodi FS, Brahmer JR, Gettinger SN, Smith DC, McDermott DF, Powderly JD, Carvajal RD, Sosman JA, Atkins MB, et al: Safety, activity, and immune correlates of anti-PD-1 antibody in cancer. N Engl J Med 366: 2443-2454, 2012.

47. Yarchoan M, Albacker LA, Hopkins AC, Montesion M, Murugesan K, Vithayathil TT, Zaidi N, Azad NS, Laheru DA, Frampton GM and Jaffee EM: PD-L1 expression and tumor mutational burden are independent biomarkers in most cancers. JCI Insight 4: e126908, 2019.

48. Pai-Scherf L, Blumenthal GM, Li H, Subramaniam S, Mishra-Kalyani PS, He K, Zhao H, Yu J, Paciga M, Goldberg KB, et al: FDA approval summary: Pembrolizumab for treatment of metastatic non-small cell lung cancer: First-line therapy and beyond. Oncologist 22: 1392-1399, 2017.

49. Abdel-Rahman O: Correlation between PD-L1 expression and outcome of NSCLC patients treated with anti-PD-1/PD-L1 agents: A meta-analysis. Crit Rev Oncol Hematol 101: 75-85, 2016.

50. Brahmer J, Reckamp KL, Baas P, Crinò L, Eberhardt WE, Poddubskaya E, Antonia S, Pluzanski A, Vokes EE, Holgado E, et al: Nivolumab versus docetaxel in advanced squamous-cell non-small-cell lung cancer. N Engl J Med 373: 123-135, 2015.

51. Davis AA and Patel VG: The role of PD-L1 expression as a predictive biomarker: An analysis of all US Food and Drug Administration (FDA) approvals of immune checkpoint inhibitors. J Immunother Cancer 7: 278, 2019.

52. Paver EC, Cooper WA, Colebatch AJ, Ferguson PM, Hill SK, Lum T, Shin JS, O'Toole S, Anderson L, Scolyer RA and Gupta R: Programmed death ligand-1 (PD-L1) as a predictive marker for immunotherapy in solid tumours: A guide to immunohistochemistry implementation and interpretation. Pathology 53: 141-156, 2021.

53. Fournel L, Wu Z, Stadler N, Damotte D, Lococo F, Boulle G, Ségal-Bendirdjian E, Bobbio A, Icard P, Trédaniel J, et al: Cisplatin increases PD-L1 expression and optimizes immune check-point blockade in non-small cell lung cancer. Cancer Lett 464: 5-14, 2019. 
54. Velcheti V, Schalper KA, Carvajal DE, Anagnostou VK, Syrigos KN, Sznol M, Herbst RS, Gettinger SN, Chen L and Rimm DL: Programmed death ligand-1 expression in non-small cell lung cancer. Lab Invest 94: 107-116, 2014.

55. Ilie M, Long-Mira E, Bence C, Butori C, Lassalle S, Bouhlel L, Fazzalari L, Zahaf K, Lalvée S, Washetine K, et al: Comparative study of the PD-L1 status between surgically resected specimens and matched biopsies of NSCLC patients reveal major discordances: A potential issue for anti-PD-L1 therapeutic strategies. Ann Oncol 27: 147-153, 2016.

56. Rimm DL, Han G, Taube JM, Yi ES, Bridge JA, Flieder DB, Homer R, West WW, Wu H, Roden AC, et al: A prospective, multi-institutional, pathologist-based assessment of 4 immunohistochemistry assays for PD-L1 expression in non-small cell lung cancer. JAMA Oncol 3: 1051-1058, 2017.

57. Büttner R, Gosney JR, Skov BG, Adam J, Motoi N, Bloom KJ, Dietel M, Longshore JW, López-Ríos F, Penault-Llorca F, et al: Programmed death-ligand 1 immunohistochemistry testing: A review of analytical assays and clinical implementation in non-small-cell lung cancer. J Clin Oncol 35: 3867-3876, 2017.

58. Vilimas T: Measuring tumor mutational burden using whole-exome sequencing. Methods Mol Biol 2055: 63-91, 2020.

59. Ready N, Hellmann MD, Awad MM, Otterson GA, Gutierrez M, Gainor JF, Borghaei H, Jolivet J, Horn L, Mates M, et al: First-line nivolumab plus ipilimumab in advanced non-small-cell lung cancer (CheckMate 568): Outcomes by programmed death ligand 1 and tumor mutational burden as biomarkers. J Clin Oncol 37: 992-1000, 2019.

60. Merino DM, McShane LM, Fabrizio D, Funari V, Chen SJ, White JR, Wenz P, Baden J, Barrett JC, Chaudhary R, et al: Establishing guidelines to harmonize tumor mutational burden (TMB): In silico assessment of variation in TMB quantification across diagnostic platforms: Phase I of the Friends of cancer research TMB harmonization project. J Immunother Cancer 8: e000147, 2020.

61. Wojas-Krawczyk K, Kalinka E, Grenda A, Krawczyk P and Milanowski J: Beyond PD-L1 markers for lung cancer immunotherapy. Int J Mol Sci 20: 1915, 2019.

62. Samstein RM, Lee CH, Shoushtari AN, Hellmann MD, Shen R, Janjigian YY, Barron DA, Zehir A, Jordan EJ, Omuro A, et al: Tumor mutational load predicts survival after immunotherapy across multiple cancer types. Nat Genet 51: 202-206, 2019.

63. Rizvi H, Sanchez-Vega F, La K, Chatila W, Jonsson P, Halpenny D, Plodkowski A, Long N, Sauter JL, Rekhtman N, et al: Molecular determinants of response to anti-programmed cell death (PD)-1 and anti-programmed death-ligand 1 (PD-L1) blockade in patients with non-small-cell lung cancer profiled with targeted next-generation sequencing. J Clin Oncol 36: 633-641, 2018.

64. Doostparast Torshizi A and Wang K: Next-generation sequencing in drug development: Target identification and genetically stratified clinical trials. Drug Discov Today 23: 1776-1783, 2018.

65. Sa H, Ma K, Gao Y and Wang D: Predictive value of tumor mutation burden in immunotherapy for lung cancer. Zhongguo Fei Ai Za Zhi 22: 380-384, 2019 (In Chinese).

66. Pisapia P, Malapelle U and Troncone G: Liquid biopsy and lung cancer. Acta Cytol 63: 489-496, 2019.

67. Gandara DR, Paul SM, Kowanetz M, Schleifman E, Zou W, Li Y, Rittmeyer A, Fehrenbacher L, Otto G, Malboeuf C, et al: Blood-based tumor mutational burden as a predictor of clinical benefit in non-small-cell lung cancer patients treated with atezolizumab. Nat Med 24: 1441-1448, 2018.

68. Nie W, Qian J, Xu MD, Gu K, Qian FF, Hu MJ, Lu J, Gan L, Zhang XY, Cao SH, et al: A non-linear association between blood tumor mutation burden and prognosis in NSCLC patients receiving atezolizumab. Oncoimmunology 9: 1731072, 2020

69. Chen YT, Seeruttun SR, Wu XY and Wang ZX: Maximum somatic allele frequency in combination with blood-based tumor mutational burden to predict the efficacy of atezolizumab in advanced non-small cell lung cancer: A pooled analysis of the randomized POPLAR and OAK studies. Front Oncol 9: 1432, 2019.

70. Zeng DQ, Yu YF, Ou QY, Li XY, Zhong RZ, Xie CM and Hu QG: Prognostic and predictive value of tumor-infiltrating lymphocytes for clinical therapeutic research in patients with non-small cell lung cancer. Oncotarget 7: 13765-13781, 2016.

71. Bodor JN, Boumber Y and Borghaei H: Biomarkers for immune checkpoint inhibition in non-small cell lung cancer (NSCLC). Cancer 126: 260-270, 2020

72. Hurkmans DP, Kuipers ME, Smit J, van Marion R, Mathijssen RHJ, Postmus PE, Hiemstra PS, Aerts JGJV, von der Thüsen JH and van der Burg SH: Tumor mutational load, $\mathrm{CD}^{+} \mathrm{T}$ cells, expression of PD-L1 and HLA class I to guide immunotherapy decisions in NSCLC patients. Cancer Immunol Immunother 69: 771-777, 2020.
73. O'Donnell JS, Long GV, Scolyer RA, Teng MW and Smyth MJ: Resistance to PD1/PDL1 checkpoint inhibition. Cancer Treat Rev 52: 71-81, 2017.

74. Memon $\mathrm{H}$ and Patel BM: Immune checkpoint inhibitors in non-small cell lung cancer: A bird's eye view. Life Sci 233 116713,2019

75. Schumacher TN and Schreiber RD: Neoantigens in cancer immunotherapy. Science 348: 69-74, 2015.

76. Wang S, He Z, Wang X, Li H and Liu XS: Antigen presentation and tumor immunogenicity in cancer immunotherapy response prediction. Elife 8: e49020, 2019.

77. Alexandrov LB, Nik-Zainal S, Wedge DC, Aparicio SA, Behjati S, Biankin AV, Bignell GR, Bolli N, Borg A, Børresen-Dale AL, et al: Signatures of mutational processes in human cancer. Nature 500: 415-421, 2013.

78. Rizvi NA, Hellmann MD, Snyder A, Kvistborg P, Makarov V, Havel JJ, Lee W, Yuan J, Wong P, Ho TS, et al: Cancer immunology. Mutational landscape determines sensitivity to PD-1 blockade in non-small cell lung cancer. Science 348: 124-128, 2015.

79. Martin AM, Nirschl TR, Nirschl CJ, Francica BJ, Kochel CM, van Bokhoven A, Meeker AK, Lucia MS, Anders RA, DeMarzo AM and Drake CG: Paucity of PD-L1 expression in prostate cancer: Innate and adaptive immune resistance. Prostate Cancer Prostatic Dis 18: 325-332, 2015.

80. Leclerc M, Mezquita L, Guillebot De Nerville G, Tihy I, Malenica I, Chouaib S and Mami-Chouaib F: Recent advances in lung cancer immunotherapy: Input of T-cell epitopes associated with impaired peptide processing. Front Immunol 10: 1505, 2019.

81. Garrido C, Paco L, Romero I, Berruguilla E, Stefansky J, Collado A, Algarra I, Garrido F and Garcia-Lora AM: MHC class I molecules act as tumor suppressor genes regulating the cell cycle gene expression, invasion and intrinsic tumorigenicity of melanoma cells. Carcinogenesis 33: 687-693, 2012.

82. Wang X, Schoenhals JE, Li A, Valdecanas DR, Ye H, Zang F, Tang C, Tang M, Liu CG, Liu X, et al: Suppression of type I IFN signaling in tumors mediates resistance to Anti-PD-1 treatment that can be overcome by radiotherapy. Cancer Res 77: 839-850, 2017.

83. Thommen DS, Schreiner J, Müller P, Herzig P, Roller A, Belousov A, Umana P, Pisa P, Klein C, Bacac M, et al: Progression of lung cancer is associated with increased dysfunction of T cells defined by coexpression of multiple inhibitory receptors. Cancer Immunol Res 3: 1344-1355, 2015.

84. Curigliano G, Gelderblom H, Mach N, Doi T, Tai D, Forde PM, Sarantopoulos J, Bedard PL, Lin CC, Hodi FS, et al: Phase I/Ib clinical trial of sabatolimab, an Anti-TIM-3 antibody, alone and in combination with spartalizumab, an Anti-PD-1 antibody, in advanced solid tumors. Clin Cancer Res 27: 3620-3629, 2021

85. Koyama S, Akbay EA, Li YY, Herter-Sprie GS, Buczkowski KA Richards WG, Gandhi L, Redig AJ, Rodig SJ, Asahina H, et al: Adaptive resistance to therapeutic PD-1 blockade is associated with upregulation of alternative immune checkpoints. Nat Commun 7: 10501, 2016.

86. Hellmann MD, Rizvi NA, Goldman JW, Gettinger SN, Borghaei H, Brahmer JR, Ready NE, Gerber DE, Chow LQ, Juergens RA, et al: Nivolumab plus ipilimumab as first-line treatment for advanced non-small-cell lung cancer (CheckMate 012): Results of an open-label, phase 1, multicohort study. Lancet Oncol 18: 31-41, 2017.

87. Hellmann MD, Ciuleanu TE, Pluzanski A, Lee JS, Otterson GA, Audigier-Valette C, Minenza E, Linardou H, Burgers S, Salman P, et al: Nivolumab plus Ipilimumab in lung cancer with a high tumor mutational burden. N Engl J Med 378: 2093-2104, 2018.

88. Bylicki O, Barazzutti H, Paleiron N, Margery J, Assié JB and Chouaïd C: First-line treatment of non-small-cell lung cancer (NSCLC) with immune checkpoint inhibitors. BioDrugs 33: 159-171, 2019.

89. Davis M, Conlon K, Bohac GC, Barcenas J, Leslie W, Watkins L, Lamzabi I, Deng Y, Li Y and Plate JM: Effect of pemetrexed on innate immune killer cells and adaptive immune T cells in subjects with adenocarcinoma of the pancreas. J Immunother 35: 629-640, 2012.

90. Javeed A, Ashraf M, Riaz A, Ghafoor A, Afzal S and Mukhtar MM: Paclitaxel and immune system. Eur J Pharm Sci 38: 283-290, 2009.

91. Borghaei H, Langer CJ, Gadgeel S, Papadimitrakopoulou VA, Patnaik A, Powell SF, Gentzler RD, Martins RG, Stevenson JP, Jalal SI, et al: 24-Month overall survival from KEYNOTE-021 Cohort G: Pemetrexed and carboplatin with or without pembrolizumab as first-line therapy for advanced nonsquamous non-small cell lung cancer. J Thorac Oncol 14: 124-129, 2019. 
92. Socinski MA, Jotte RM, Cappuzzo F, Orlandi F, Stroyakovskiy D, Nogami N, Rodríguez-Abreu D, Moro-Sibilot D, Thomas CA, Barlesi F, et al: Atezolizumab for first-line treatment of metastatic nonsquamous NSCLC. N Engl J Med 378: 2288-2301, 2018.

93. Aupérin A, Le Péchoux C, Rolland E, Curran WJ, Furuse K, Fournel P, Belderbos J, Clamon G, Ulutin HC, Paulus R, et al: Meta-analysis of concomitant versus sequential radiochemotherapy in locally advanced non-small-cell lung cancer. J Clin Oncol 28: 2181-2190, 2010.

94. Jarosz-Biej M, Smolarczyk R, Cichoń T and Kułach N: Tumor microenvironment as a 'game changer' in cancer radiotherapy. Int J Mol Sci 20: 3212, 2019

95. Barker HE, Paget JT, Khan AA and Harrington KJ: The tumour microenvironment after radiotherapy: Mechanisms of resistance and recurrence. Nat Rev Cancer 15: 409-425, 2015.

96. Deng L, Liang H, Burnette B, Beckett M, Darga T, Weichselbaum RR and Fu YX: Irradiation and anti-PD-L1 treatment synergistically promote antitumor immunity in mice. J Clin Invest 124: 687-695, 2014.

97. Gong X, Li X, Jiang T, Xie H, Zhu Z, Zhou F and Zhou C: Combined radiotherapy and anti-PD-L1 antibody synergistically enhances antitumor effect in non-small cell lung cancer. J Thorac Oncol 12: 1085-1097, 2017.

98. Theelen WSME, Peulen HMU, Lalezari F, van der Noort V de Vries JF, Aerts JGJV, Dumoulin DW, Bahce I, Niemeijer AN, de Langen AJ, et al: Effect of pembrolizumab after stereotactic body radiotherapy vs pembrolizumab alone on tumor response in patients with advanced non-small cell lung cancer: Results of the PEMBRO-RT phase 2 randomized clinical trial. JAMA Oncol 5: 1276-1282, 2019

99. Li JX, Huang JM, Jiang ZB, Li RZ, Sun A, Lai-Han Leung E and Yan PY: Current clinical progress of PD-1/PD-L1 immunotherapy and potential combination treatment in non-small cell lung cancer. Integr Cancer Ther 18: 1534735419890020, 2019

100. Habas K, Nganwuchu C, Shahzad F, Gopalan R, Haque M, Rahman S, Majumder AA and Nasim T: Resolution of coronavirus disease 2019 (COVID-19). Expert Rev Anti Infect Ther 18 1201-1211, 2020.
101. DU HZ, Hou XY, Miao YH, Huang BS and Liu DH: Traditional Chinese Medicine: An effective treatment for 2019 novel coronavirus pneumonia (NCP). Chin J Nat Med 18: 206-210, 2020

102. Wood SL, Pernemalm M, Crosbie PA and Whetton AD: The role of the tumor-microenvironment in lung cancer-metastasis and its relationship to potential therapeutic targets. Cancer Treat Rev 40: 558-566, 2014.

103. Wang Y, Zhang Q, Chen Y, Liang CL, Liu H, Qiu F and Dai Z: Antitumor effects of immunity-enhancing traditional Chinese medicine. Biomed Pharmacother 121: 109570, 2020.

104. Liao CH, Yong CY, Lai GM, Chow JM, Cheng CF, Fang CL, Lin PC, Chang CL, Zheng YM, Chuang SE, et al: Astragalus polysaccharide (PG2) suppresses macrophage migration inhibitory factor and aggressiveness of lung adenocarcinoma cells. Am J Chin Med 48: 1491-1509, 2020.

105. Li W, Hu X, Wang S, Jiao Z, Sun T, Liu T and Song K Characterization and anti-tumor bioactivity of astragalus polysaccharides by immunomodulation. Int J Biol Macromol 145 985-997, 2020

106. Bamodu OA, Kuo KT, Wang CH, Huang WC, Wu ATH, Tsai JT, Lee KY, Yeh CT and Wang LS: Astragalus polysaccharides (PG2) enhances the M1 polarization of macrophages, functional maturation of dendritic cells, and T cell-mediated anticancer immune responses in patients with lung cancer. Nutrients 11: 2264, 2019.

107. Wang HB, Zheng QY, Qian DH, Fang J and Ju DW: Effects of Phytolacca acinosa polysaccharides I on immune function in mice. Zhongguo Yao Li Xue Bao 14: 243-246, 1993.

108. Chen Y, Wang Y, Xu L, Zhu W, Xu C, Xu M, Guo L, Hu W, $\mathrm{Xu} \mathrm{D}$, Jing R, et al: Influence of total glucosides of paeony on PD-1/PD-L1 expression in primary Sjögren's syndrome. Int J Rheum Dis 22: 200-206, 2019. International (CC BY-NC-ND 4.0) License. 